\title{
AVALIAÇÃO MÉDICO-FORENSE DA CAPACIDADE E DA RESPONSABILIDADE
}

\author{
Sebastião André de Felice \\ Issao Kameyama ${ }^{2}$
}

Resumo:

Os autores estudam o papel da Medicina Forense na avaliação pericial da capacidade civil e da responsabilidade penal. Apresentam diversas situaçðes em que esta avaliação pericial é indispensável ao juiz.

\begin{abstract}
:
The authors study the paper of Forensic Medecine in evaluation of the capacity and the responsability. Introducing diverses situations in with this expert evaluation is vital to the judge.
\end{abstract}

A capacidade civil e a responsabilidade penal são conseqüências diretas das características da personalidade jurídica, entendendo-se por personalidade juridica a aptidão, reconhecida juridicamente, de exercer direitos e contrair obrigações.

A capacidade civil pode ser de direito ou de gozo e de fato ou de exercício.

A capacidade de exercício é influenciada por numerosos fatores, tais como a idade, o sexo, a alienação mental, para citar apenas alguns exemplos.

A idade já era considerada como condicionante da capacidade civil no Direito Romano, como nos ensina o Professor Moreira Alves, ${ }^{3}$ condicionando-a à puberdade, ou seja, à capacidade procriativa, avaliada pelo exame físico, o que prevaleceu até o Código Justiniano, quando passou a prevalecer o critério etário.

1. Superintendente do Instituto de Medicina Social e Criminologia de São Paulo (IMESC). Professor do Departamento de Prática de Saúde Púbica da Faculdade de Saúde Pública da USP e Professor Colaborador do Departamento de Medicina Forense e Criminologia da Faculdade de Direito da USP. Paulo.

2. Professor de Medicina Legal da Faculdade de Direito da Pontificia Universidade Católica de São

3. José Carlos Moreira Alves, Direito Romano, 7 ed., Rio de Janeiro, Forense, 1991. 
$O$ próprio início da personalidade jurídica, com o conseqüente começo da capacidade de direito ou de gozo, isto é, a capacidade de ter direitos, dáse com o nascimento, conforme disposto no art. $4^{\circ}$ do Código Civil, ensejando oportunidades de intervenção da Medicina Forense, pois o aludido dispositivo legal exige que o recém-nascido esteja vivo, bastando, segundo ensinamento do Professor Sílvio Rodrigues, ${ }^{4}$ para que se dê o surgimento da personalidade jurídica, que o nascido tenha nascido vivo, pouco importando o tempo durante o qual viveu ou suas condições de viabilidade. Não tem agasalho na nossa legislação vigente a exigência de viabilidade que encontramos em legislações pretéritas ou estrangeiras. Basta que naş̧a vivo.

Não é mais aceitável o velho conceito de Galeno, para quem viver é respirar. $\mathrm{O}$ art. 23 da Constituição Mundial da Saúde ${ }^{5}$ define como nascido vivo o ser que, após a separação do corpo materno, dê qualquer sinal de vida, seja uma inspiração, uma contração muscular voluntária, batimentos cardíacos, etc. Não é outra a conceituação do Professor Washington de Barros Monteiro. ${ }^{6}$

Daí o grande valor da contribuição da Medicina Forense, ao provar que o nascimento foi de um ser vivo, dada a enorme relevância jurídica deste fato, especialmente no que se refere ao campo sucessório, para não sairmos do âmbito civil.

Não mais são aceitáveis, como exclusivas provas de vida, as docimasias, pois estas só fornecem informações quanto à respiração e este é apenas uma das possíveis provas de vida, nunca a única.

Superada a problemática do início da capacidade jurídica de direito ou de gozo, temos que nos reportar à capacidade de fato ou de exercício, que é, no dizer dos civilistas, à testa dos quais Bevilácqua, ' a aptidão para praticar pessoalmente atos de relevância jurídica.

O critério etário parece-nos o mais indicado, sendo o adotado pela nossa legislação.

4. Direito Civil, $18^{\star}$ ed., São Paulo, Saraiva, 1993.

5. Organização Mundial da Saúde, Constituição-Documentos Básicos, separata, s. I., s. n., 1985.

6. Curso de Direito Civil, $18^{2}$ ed., São Paulo, Saraiva, 1983.

7 Clóvis Bevilácqua, Código Civil dos Estados Unidos do Brasil, 10 ed., Rio de Janeiro, Francisco Alves, 1953. 
A lei baseia-se, ao fazê-lo, na pressuposição de que o desenvolvimento mental e emotivo do indivíduo é incompleto antes dos 16 anos, sendo ele, então, incapaz de exprimir validamente sua vontade.

Dispõe o Código Civil que entre os 16 e os 21 anos a capacidade é relativa, ou seja, a capacidade de fato existe, mas deve ser amparada por pessoa de maior experiência, como os pais ou os tutores.

Somente a partir dos 21 anos é que se admite ser a capacidade de fato completa.

O papel da Medicina Forense na determinação da idade é curial e sua importância extrema quando nos aproximamos das idades limites (16 e 21 anos), exigindo técnicas periciais às vezes complexas.

Em relação ao sexo como fator condicionante da capacidade de fato, 0 Direito Romano só concedeu às mulheres a paridade com os homens a partir do século IV d.C.

As poucas restrições existentes na nossa legislação quanto à capacidade de fato, em relação ao sexo feminino, foram eliminadas e, tendo deixado de existir, não mais interessam à Medicina Forense.

Já o contrário acontece com as anomalias mentais, cuja avaliação depende quase que exclusivamente da Medicina Forense.

O Direito Romano, em relação ao problema das alienações mentais, classificava seus portadores em furiosi, dementes e mentecapti, para diferenciar a alienação completa da parcial ou debilidade mental. Justiniano, segundo nos ensinam Biondi ${ }^{8}$ e Moreira Alves, ${ }^{9,10}$ desprezou esta divisão, enfaixando-os numa categoria única, reconhecendo a todos a necessidade de um curador.

Nosso Código Civil não entra, nem poderia entrar, como o fizeram legislações pátrias pretéritas, na conceituação ou diferenciação das alienações mentais. Segue a orientação justiniana: aqueles que, por desenvolvimento cerebral incompleto ou por moléstia situada no encéfalo, gozam de equilíbrio mental e clareza de raciocínio insuficientes para o convívio social normal são juntados num feixe único sob a rubrica de "loucos de todos os gêneros"

8. B. Biondi, Existenzialismo Giuridico e Giurisprudenza Romana in Studi Juridici in Onore di Francesco Carnelluti, Pádua, Cedam, 1950.

9. Ibidem.

10. Ibidem. 
Justifica-se a posição do legislador pois, como destaca Bevilácqua," ao mundo jurídico não interessa um diagnóstico mórbido e sim a adequação ou inadequação do indivíduo à vida social.

À Medicina Forense cabe importante papel na discriminação entre capacidade e incapacidade, pois a determinação da mesma é fortemente influenciada pelo exame pericial. Podemos ir mais longe: depende da Medicina Forense não só a distinção pericial entre capacidade e incapacidade, como também sua quantificação, caracterizando se o indivíduo é absoluta ou relativamente incapaz.

Ainda dentro do capítulo das incapacidades devemos lembrar que o Código Civil, no $\S 3^{\circ}$ do art. $5^{\circ}$ inclui os surdos-mudos, embora não haja concordância dos autores a este respeito.

Alguns autores insurgem-se contra tal dispositivo, considerando que surdos-mudos estão impossibilitados apenas de exercer pessoalmente certos atos. Nina Rodrigues ${ }^{12}$ opina o contrário pois, quer seja a surdo-mudez de origem prénatal ou adquirida, é evidente a dificuldade de aprendizado e de manifestação de vontade.

Parece-nos bizantina esta disputa, pois há surdos-mudos cuja surdomudez é de origem anterior ao parto dos "loucos de todos os gêneros" e surdosmudos cuja surdo-mudez foi adquirida após o parto. Cabe à Medicina Forense decidir, frente a cada concreto, qual das duas hipótese se aplica. É curial que, sendo o surdo-mudo educável, é função da perícia médico-forense determinar o grau de entendimento e de expressão de vontade do paciente, para permitir ao juiz emitir sua decisão em bases sólidas.

Não se compreende porque o legislador não deu aos surdos-mudos o mesmo tratamento dado aos cegos, aos velhos ou aos condenados que, embora impossibilitados de exercerem pessoalmente certos atos, nem por isto são interditados.

Já Nina Rodrigues opinava o contrário pois, seja a surdo-mudez de origem pré-natal ou pós-natal, é evidente a dificuldade de aprendizado e de manifestação de vontade.

11 Ob. cit.

12. O Alienado no Direito Civil Brasileiro, Rio de Janeiro, Guanabara, 1933. 
O problema da surdo-mudez não compensada é antigo. O Direito Romano impedia o surdo-mudo de testar e as restrições à sua capacidade encontram-se em numerosas legislações.

Sendo o surdo-mudo potencialmente educável, cabe à perícia médicoforense determinar o grau de entendimento e de expressão de vontade do paciente, permitindo ao juiz emitir sua decisão em bases cientificamente sólidas.

Como último fator incapacitante, o nosso Código Civil, retomando a posição do Direito Romano, elenca a prodigalidade. Nesses casos o auxílio da Medicina Forense, através da Psicopatologia Forense, é indispensável, pois existem moléstias mentais que se caracterizam pela oniomania, isto é, a prodigalidade.

Diante de um pedido de interdição por prodigalidade, freqüentemente ditado pela cobiça de familiares, o juiz precisa da contribuição pericial médicoforense.

Embora o Código Civil não tenha elencado a cegueira ou a velhice entre as causas incapacitantes, casos existem em que a declaração de incapacidade impõe-se. Vejamos: a cegueira deve ser constatada e avaliada pela perícia médicoforense, sendo isto indispensável para que 0 ato jurisdicional declare como deve ser suprida a deficiência física do cego.

$\mathrm{Na}$ senilidade encontram-se os mais variados graus de alteração mental, desde a perfeita higidez até a completa alienação. Saulle ${ }^{13}$ lembra que na senilidade há um rebaixamento da inteligência, sem chegar, porém, à demência. Com acerto afirma Tardieu ${ }^{14}$ que a senilidade, embora acarrete maior sugestionabilidade, não implica forçosamente a impotência da vontade e nem macula sempre a capacidade de realizar certos atos. Da mesma opinião é a maioria dos civilistas pátrios.

A Medicina Forense deve se ouvida, com freqüência, não apenas para estabelecer a incapacidade, mas também para decidir-se de sua cessação.

O fim da personalidade jurídica e com ela o término da capacidade de direito e de fato, segundo disposto no art. 10 do Código Civil, ocorre com a morte, pois com ela desaparece o sujeito de direitos e obrigações definido no art. $1^{\circ}$ do mesmo instituto legal, desde que não mais aceita a morte civil.

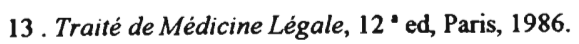

14. Étude Psichologique, Rev. Philosophique, 1905. 
Um fato tão corriqueiro como a morte cria problemas seriíssimos para a Medicina Forense, pois o conceito de morte e o momento de sua ocorrência não são conceitos remansosos, antes, pelo contrário, são extremamente controversos e capazes de levantar problemas médico-forenses graves quando aplicados ao caso concreto.

Basta lembrar os problemas que se apresentam à Medicina Forense, quando surge a necessidade de se estabelecer a premoriência ou a comoriência, isto é, a necessidade de ordenar cronologicamente duas mortes, para resolver problemas sucessórios, desde que nossa legislação não aceita as presunções do Direito Romano ou das legislações européias do século passado, como consta do art. 11 do Código Civil; por outro lado, as dificuldades que estes problemas apresentam à Medicina Forense são tantas, que os clássicos trabalhos de Foderé ${ }^{15}$ e de Orfila ${ }^{16}$ continuam atuais, ao afirmarem que pouco se pode esperar da Medicina Forense nos casos de comoriência.

Como dissemos, o conceito de morte encerra algumas dificuldades, pois ao invés de ser um fenômeno instantâneo, estende-se no tempo. A morte não é um momento e sim um processo, como destaca com muita propriedade Oliveira Sá. ${ }^{17}$

O processo morte estende-se por três etapas em fases: a de morte relativa, a de morte intermediária e a de morte absoluta.

Sendo necessário fixar, neste evoluir do fenômeno que é a morte, o momento em que finda a personalidade jurídica, somos obrigados a nos deter na descrição dos fenômenos mortuários.

Na primeira fase, a de morte relativa, ocorre a suspensão real, porém não definitiva, das funções vitais, portanto suspensão ainda reversível. Não dispomos atualmente de nenhum sinal (parada cardiorespiratória) ou exame subsidiário (eletrocardiograma, eletroencefalograma) que permita afirmar, diante do caso concreto, se a morte é reversível ou não.

Só o resultado dos esforços reanimadores decifra o enigma: se o paciente recuperar as funções vitais é prova de que se encontrava ainda nesta fase;

15. Traité de Médicine Légale et d'Hygiène Publique ou de Police de Santé, Paris, Mame, 1816.

16. Traité de Médicine Légale, $3^{\circ}$ ed. , Paris, Boechet Jeune, 1836.

17. Sá, F. M. Oliveira, Cronotanatognose (tese), Coimbra, 1966. 
se não se conseguir reanimá-lo, é que a mesma já tinha sido ultrapassada. Por outras palavras, o que caracteriza a fase de morte relativa é sua reversibilidade.

Na segunda fase, a chamada morte intermediária, a irreversibilidade do fenômeno mortuário está instalada e nela aparecem os sinais clássicos da morte: rigidez muscular, aotólise enzimática, hipósteses, etc. Nesta fase, pese à irreversibilidade que a caracteriza, estão ainda presentes algumas funções vitais, que aos poucos vão se apagando, à medida que se esgota seu potencial energético, até atingirmos a terceira fase, a da morte absoluta, em que desaparecem todas as funções vitais.

Do exposto conclui-se que o momento da morte jurídica deve localizar-se no fim da fase de morte relativa. Se continuarmos com a conceituação prevalente, isto é, identificar o momento da extinção da personalidade jurídica com o início da morte relativa, caracterizada pela parada cardiorespiratória, corremos o risco de termos de enfrentar situações de alcance jurídico muito complexas.

No momento em que se decide ter acontecido a morte legal extinguese a personalidade jurídica, conforme disposto no art. 10 do Código Civil, para transformar-se o homem em cadáver, em res extracomercium. Com 0 desaparecimento da pessoa física extingue-se sua capacidade de direito, tendo isto profunda repercussão no mundo jurídico: extinção do vínculo matrimonial; conseqüências sucessórias; extinção de punibilidade, para citar apenas alguns exemplos.

Na hipótese da extinção da personalidade juridica pela decretação jurídica da morte ainda em fase de morte relativa e recuperada, posteriormente, a vida por manobras reanimadoras, estaremos frente a uma nova personalidade civil, o que colidiria com o disposto no art. $4^{\circ}$ do Código Civil, acarretando conseqüências jurídicas extremamente esdrúxulas: o "ressuscitado" seria o exmarido de sua própria viúva, figura desconhecida, por absurdo, do nosso direito; ter passado o patrimônio aos herdeiros, ficando o " ressuscitado" privado de seus bens, e assim por diante.

É óbvio que o esdrúxulo destas situações obriga a fixar o momento jurídico da morte, quando não mais haja possibilidade de reanimação, isto é, no início da fase de morte intermediária. A dificuldade prática que se apresenta à Medicina Forense, no estágio atual de nossos conhecimentos do processo letal, é detectar este momento, pois atualmente só o reconhecemos a posteriori: se as 
manobras reanimadoras têm sucesso é que ainda está na fase de morte relativa; se não têm sucesso é que já se encontra na fase de morte intermediária.

Isto mostra os graves problemas a serem enfrentados pela Medicina Forense ao se defrontar com a questão do término da capacidade civil.

Passemos ao estudo na responsabilidade penal.

O Código Penal não define responsabilidade, limitando-se a referirse a ela com expressões do tipo "é isento de pena", "a pena pode ser reduzida", "são circunstâncias que sempre agravam a pena" e assim por diante. Por outro lado, sabemos ser a responsabilidade a base da imputabilidade.

A doutrina conceitua a imputabilidade como a aptidão para realizar com pleno discernimento um ato; para que isto aconteça é preciso que o agente tenha pleno desenvolvimento e normalidade mentais.

Diz o art. 26 do Código Penal que "é isento de pena o agente que, por doença mental ou desenvolvimento mental incompleto ou retardado, era, ao tempo da ação ou da omissão, inteiramente incapaz de entender o caráter criminoso do fato ou de determinar-se de acordo com esse entendimento"

Este dispositivo mostra que a responsabilidade depende de dois elementos basilares: o cognitivo e o volitivo, de tal maneira que qualquer perturbação num deles abala definitivamente a responsabilidade do agente, levando-o à inimputabilidade ou a semi-imputabilidade. $\mathrm{O}$ art. 26 do Código Penal, como vimos, é explícito a este respeito.

O elemento cognitivo encontra-se na expressão "entender o caráter criminoso do fato" e o elemento volitivo na locução "determinar-se de acordo com este entendimento"

É de se observar que o Código Penal, ao identificar o elemento volitivo, não abraça a teoria defensora do livre-arbítrio: entende por elemento volitivo a capacidade de determinar-se, próprio da vida comum, fugindo, assim, à longa e infrutífera discussão entre deterministas e livre-arbitristas.

$\mathrm{O}$ art. 26 do Código Penal exige, ainda, para tornar inimputável o agente, que os elementos de responsabilidade tenham sido afetados por "doença mental ou desenvolvimento mental incompleto ou retardado" A responsabilidade sofre apenas diminuição se os elementos cognitivo e volitivo tivessem sido parcialmente atingidos; a responsabilidade, neste caso, permanece, porém, diminuída. 
Existem dois sistemas básicos de se avaliar a responsabilidade, como bem lembra Basileu Garcia, ${ }^{18}$ o biológico, segundo o qual a simples presença da doença é suficiente para se decretar a inimputabilidade, sem se procurar avaliar a influência que a mesma teve no ato ilícito e o sistema psicológico, que não se ocupa em pesquisar se existe moléstia mental, preocupado, apenas, em avaliar a perturbação da percep̧̧ão antijurídica do ato no momento de perpetrá-lo.

Nosso código segue o sistema biopsicológico, que é um misto dos dois sistemas básicos: considera a existência da moléstia mental ou da minus-valia e lhes avalia a influência no ato criminoso.

A maioria dos códigos penais modernos filiam-se ao sistema biopsicológico, como é o caso do argentino, do italiano ou do suíço.

Pelo sistema adotado no Código Penal pátrio o indivíduo mentalmente enfermo, se no momento de cometer o crime estava lúcido, será considerado imputável, pois sua doença não perturbou o elemento cognitivo nem o volitivo, no momento do ato criminoso.

Por outro lado, há doenças psíquicas que podem influir em determinadas condutas e não o fazerem em outras. Por exemplo, o paranóico com mania persecutória pode matar, acreditando que se defende de séria ameaça. Neste caso será considerado inimputável, mas, se ao invés de matar, praticar um estupro ou um furto, a doença de que é vítima em nada lhe diminuirá a responsabilidade.

Cabe à Medicina Forense decidir do grau de causalidade existente entre o ato criminoso e a perturbação mental. Com razão Basileu Garcia ${ }^{19}$ quando afirma que "a palovra dos peritos psiquiatras, ainda que não vincule o juiz, é sempre fundamental à decisão"

O problema apresentado pelos chamados intervalos lúcidos não é remansoso. Assim, Lutz acredita que, apesar da remissão dos sintomas, perdure o quadro patológico, ou seja, na chamada remissão ocorre que a moléstia evolui abaixo do horizonte clínico, embora em fase assintomática possa influir na conduta criminosa ou não.

A escola biopsicológica, a que se filiam nossos legisladores penais, resolve o tormentoso problema dos chamados loucos morais ou, como prefere Alves

18. Instituiçðes de Direito Penal, 4“ ed., São Paulo, Max Limonad, 1977.

19. Ibidem. 
Garcia, ${ }^{20}$ psicopatas amorais, pois desde que sua anormalidade não seja produzida por enfermidade mental, não merecem o beneficio da inimputabilidade. Esta é a opinião da maioria dos autores, entre os quais destacam-se Nério Rojas ${ }^{21}$ e Di Tullio. $^{22}$

$\mathrm{O}$ art. 26 do Código Penal refere-se, além dos doentes mentais, aos que têm desenvolvimento mental incompleto ou retardado. É óbvio que esta categoria deve incluir, além dos oligofrênicos nas suas várias graduações (idiotia, imbecilidade, etc.), aqueles que não puderam, por diversas razões, completar seu desenvolvimento mental. Assim ocorre, por exemplo, com os silvícolas nãoaculturados ou os surdos-mudos não-educados, pois pode faltar-lhes o elemento cognitivo da antijuricidade do ato praticado. Não sendo completa sua formação moral, podem não entender o caráter criminoso de seu ato. Por exemplo, um índio não-aculturado, em cuja cultura não exista o conceito de propriedade, não pode entender que comete um crime quando se apropria de objeto que não lhe pertença.

Quando o médico forense lavra um laudo capaz de enquadrar um réu no art. 26, deve fazê-lo com o máximo cuidado, pois se o laudo for acolhido pelo juiz, o réu será declarado irresponsável e encaminhado ao manicômio judiciário, onde ficará sujeito a medidas de segurança detentivas que perdurarão até que outro laudo médico declare cessada sua periculosidade, conforme disposto no art. 775 do Código de Processo Penal.

As dicotomias puras inexistem na natureza, isto é, a população não se divide em indivíduos sãos e em indivíduos doentes: entre estes dois extremos encontram-se todas as graduações possíveis, logo deve haver, também, entre os responsáveis e os totalmente irresponsáveis toda a gama gradativa de irresponsabilidades parciais. É o que levou em consideração o legislador ao redigir o parágrafo único do art. 26 do Código Penal. Cabe papel relevante ao perito para avaliar o grau de imperfeita compreensão do ato criminoso ou o grau de dificuldade em determinar-se de acordo com esta compreensão, possibilitando, ao fazê-lo, que o juiz possa avaliar o grau de responsabilidade do réu.

20 Garcia, J. Alves, Psicopatologia Forense, 3' ed., Rio de Janeiro, Forense, 1979.

21. Medicina Legal, 11' ed., Buenos Aires, El Ateneo, 1976.

22. Tullio, B. di, Tratado de Antropologia Criminal, Buenos Aires, Inst. Panamericano de Cultura, 1950. 
São precisamente estes indivíduos limítrofes da normalidade, também chamados de fronteiriços ou personalidades psicopáticas os que mais exigem da Psicopatologia Forense, pois, integrados que estão na comunidade e portadores de uma sintomatologia discreta, tornam-se elementos perigosíssimos. O próprio Código Penal, em certos casos, como o do parágrafo único do art. 83, alude de maneira insofismável à periculosidade do agente.

Outro problema que afeta a Medicina Forense é a idade do agente. $O$ Código Penal, através de seu art. 27, considera completamente irresponsáveis os menores de dezoito anos de idade. Cabe, portanto, à Medicina Forense resolver às vezes os problemas que decorrem da necessidade de fixar a idade do agente.

Falta ainda estudar o problema das perturbações transitórias da higidez mental produzidas pelo álcool ou substância de efeitos semelhantes. É da responsabilidade da Medicina Forense determinar a intensidade da intoxicação e o grau em que a mesma alterou a higidez mental do agente, ficando para as autoridades judiciárias decidir se a intoxicação foi por ato voluntário ou culposo, por caso fortuito ou força maior ou preordenado.

É de se observar que as perícias médico-forenses nos casos de alcoolismo são sempre feitas a posteriori, o que diminui grandemente o valor. As fórmulas apresentadas para estimar o grau de alcoolemia no momento do ilícito penal não são confiáveis, pois não levam em conta as variáveis individuais, como a do coeficiente de etiloxidação, por exemplo, e porque nem sempre o grau de embriaguez equivale ao grau de alcoolemia, havendo grande variabilidade de pessoa para pessoa. A mesma alcoolemia pode não ser embriagante num bebedor contumaz e ser altamente embriagante numa pessoa abstêmia.

Novo capítulo levanta-se diante da Medicina Forense, infelizmente com relevância social e penal crescentes, originado pelo uso dos fármacodependentes.

O Código Penal ao falar no inciso Il do art. 28 em substâncias e efeitos análogos aos do álcool, dando-lhes o mesmo tratamento que a este fármaco, não resolve satisfatoriamente o problema, pois são inúmeras as substâncias fármaco-dependentes de efeitos muito diferentes aos do álcool. Enquanto que este deprime o sistema nervoso central, as substâncias psicoanalépticas o estimulam e as psicodislépticas nem o deprimem nem o estimulam, alterando-lhe a atividade, levando-o às alucinações. 
Felizmente a Lei n. 6.368 , no seu art. 19 , praticamente transcreve o art. 28 do Código Penal, tornando-o extensivo a todas as substâncias drogaditas.

Não podemos esquecer o art. 123 do Código Penal, segundo o qual a autora de infanticídio tem a pena reduzida, numa clara demonstração de que considera o estado puerperal como causa de irresponsabilidade parcial. Ora, a perturbação do estado puerperal e, inclusive, sua própria existência, é um dos temas mais controvertidos em Psicopatologia Forense, pois não são poucos os autores que se recusam a aceitar uma perturbação mental tão grave, ao extremo de causar a morte do próprio filho, e tão breve, que termina em poucas horas ou poucos dias após o parto, o que a torna de avaliação pericial sempre a posteriori. Acham estes autores, e com razão, que no máximo pode aceitar-se uma doença mental de evolução subclínica, prévia ao parto e que, por ocasião deste, apresenta um surto psicótico para voltar, logo após, novamente, à evolução subclínica e que neste caso é perfeitamente aplicável o previsto no art. 26 do Código Penal, sendo dispensável, por inútil, o art. 123 do mencionado instrumento legal.

Lembremos, ainda, que algumas doenças somáticas podem ser responsáveis por perturbações de conduta, capazes de tipificar atos delituosos. É da alçada da Medicina Forense descobrir a existência de tais moléstias e estimar o grau de influência das mesmas na conduta ilícita.

Para encerrar, queremos lembrar o ensinamento de Gilbert Ballet ${ }^{23}$ de que aos peritos médicos não cabe referir-se à responsabilidade ou irresponsabilidade do peritado, devendo-se limitar a pronunciar-se sobre a realidade e a natureza das perturbações mentais do mesmo, pois as noções de responsabilidade e de irresponsabilidade são de ordem filosófica e jurídica, jamais de ordem médica.

Ao não atender à recomendação de Ballet, o médico invade a seara jurídica, excedendo-se em suas funções e, não raro, incorrendo em graves erros. 